\title{
ANALISIS KOMAPARASI TARIF SEWA ANGKUTAN WISATA AIR DALAM KOTA PALEMBANG ( STUDI KASUS DERMAGA BKB KE TUJUAN WISATA MUSI )
}

\author{
Chairul I. Ilham ATD.MM \\ Dosen STTD \\ J1. Raya Setu no.89 \\ Cibuntu Cibitung
}

\author{
Drs.Anwar.MM \\ Dosen STTD \\ J1. Raya Setu no.89 \\ Cibuntu Cibitung
}

\author{
DR.Kusnendy Msi \\ Dosen STTD \\ Jl. Raya Setu no.89 \\ Cibuntu Cibitung
}

\author{
Purboyo Spd.Msi \\ Dosen STTD \\ J1. Raya Setu no.89 \\ Cibuntu Cibitung
}

Tlp/Fax: ( 021 ) 8254640 Tlp/Fax : ( 021 ) 825464 Tlp/Fax : ( 021 ) 8254640 Tlp/Fax : ( 021 ) 8254640

\begin{abstract}
Issues that developed in the implementation tariff in the river Musi has not explored aspects of social economic anf financial pricing (tariff) transportation that is in use or eforced at this time.In this research, the analysis is done by condructing a survey anf tariff calculation study which is indicator on the price in rupiah perkilometer ( KM 73 Year 2004 ) but on the other side also conducted a study on how to share the tariff desired by the passegers/ tourist and the operator of the ship itself. And indeed between the price share offered by the operator when compared with the ability to pay and the desire to pay passengers ( willingness to pay and ability to pay) that the value of both price deviation almost not different or about 2,5-3,0\%, but when compared with the calculation result based on distance tariff ( KM 73/2004 ) THAT GETEK PRICE Rp. 192.600 / ship / trip and speedboat Rp. 179.760 / ship / trip. This price is lower about 50 percent offered the operator and the desire and ability to pay passengers tours. Given the highlevel of calculation gap, it is necesssary to review more specific provisions for tourist boat tariff
\end{abstract}

Keyword : Tariff, ship, passengers, operator, getek, speed boat

\begin{abstract}
ABSTRAKSI
Issue yang berkembang dalam pemberlakuan tariff angkutan wisata di sungai musi belum menggali aspek social ekonomi maupun financial harga(tariff) angkutan yang di gunakan atau diberlakukan pada saat ini. Pada penelitian ini dilakukan analisis dengan melakukan survai dan kajian perhitungan tariff yang ber indicator pada harga dalam rupiah perkilometer( KM 73 Tahun 2004), namun dilain pihak dilakukan juga kajian bagaimana share tariff yang diinginkan penumpang/wisatawan serta operator kapalnya sendiri.

Dan sesungguhnya antara share harga yang ditawarkan operator bila dibandingkan dengan kemampuan membayar dan keinginan membayar penumpang (Willingness to pay and ablity to pay) bahwa nilai deviasi harga keduanya hamper tidak jauh berbeda atau sekitar 2,5-3,0 persen.

Tetapi bila dibandingkan dengan hasil perhitungan yang berdasarkan tariff jarak(KM 73/2004), bahwa getek harganya Rp 192.600/kapal/trip dan speedboat Rp 179.760/kapal/trip. Harga ini lebih rendah sekitar 50 persen dari harga yang ditawarkan operator maupun keinginan dan kemampuan membayar penumpang wisata. Mengingat tingkat kesenjangan perhitungan yang cukup tinggi, maka perlu dikaji lagi ketentuan khusus untuk tariff kapal wisata.
\end{abstract}

Kata kunci : Tarif,kapal,penumpang,operator,getek, speed boat. 


\section{PENDAHULUAN}

\section{LATAR BELAKANG}

Kota Palembang merupakan ibukota dari Provinsi Sumatera Selatan yang terdiri dari 14 kecamatan seluas $400,61 \mathrm{Km}^{2}$ dengan jumlah penduduk 1451.776 jiwa. Secara geografis terletak pada posisi antara $2^{\circ} 52^{\prime}-3^{\circ} 5^{\prime}$ LS dan $104^{\circ} 37^{\prime}-104^{\circ} 52^{\prime \prime}$ BT. Kota Palembang memiliki beberapa sungai salah satunya yaitu Sungai Musi yang merupakan sungaii terpanjang di Indonesia. Mempunyai panjang keseluruhan yang mencapaii $\pm 700 \mathrm{~km}$ dan yang dapat dilayari $\pm 450 \mathrm{~km}$ menjadikan Sungai Musii mempunyai peranan penting dalam menunjang perekonomian masyarakat Kota Palembang melalui angkutan sungai.

Saat dilakukan wawancara dengan penumpang didapatkan imformasi banyak operator taksi air yang mematok tarif trayek berdasarkan harga negoisasi antara operator dengan pengguna jasa, padahal dalam penetapan tarif sudah ada peraturan yang mengatur hal tersebut yaitu KM 73. Tahun 2004 disamping juga ada juga pendekatan tariff yang di dasarkan oleh konsumen.( Ablity To Pays Tariff). Dalam penulisan ini kami mencoba meneliti kemampuan konsumen dalam membayar tariff angkutan,serta membandingkan dengan ketentuan yg ditetapkan oleh pemerintah, yang dimaksudkan dalam penelitian ini apakah cukup memadai tariff yang diterapkan berdasarkan peraturan tersebut dan kemampuan membayar dari konsumens yang ekivalen dengan pelayanan ekonomi , selain itu juga belum adanya penetapan tarif mengenai biaya rental atau sewa angkutan air yang ditetapkan oleh pemerintah kota Palembang.Berdasarkan issue yang berkembang tersebut tersebut, maka judull Penelitian ini adalah ANALISIS KOMAPARASI TARIF SEWA ANGKUTAN WISATA AIR DALAM KOTA PALEMBANG (STUDI KASUS DERMAGA BKB KE TUJUAN WISATA MUSI".)

\section{Perumusan Masalah}

Memperhatikan issue yang dikembangkan dalam melatar belakangi penulisan judul penelitian ini,dilakukan upaya yang positif dengan cara menggali aspek ekonomis social maupun financial harga angkut wisata di sungai musi dengan harapan dapat ditemukan tariff ideal angkutan wisata di sungai musi. Baik itu dari sisi konsumen maupun pihak operator kapal nya sendiri yang dapat diterapkan dalam penyewaan taksi air didalam kota Palembang seusai dengan perhitungan Biaya Operasional Kapal.yang secara legalitas ditentukan oleh keputusan Menteri Perhubungan NO KM 73/2004,namun dilain pihak apakah ketentuan tersebut sudah mengakomodir, kemapuan wisatawan dan keinginan operator ankutan wisata air yg operasi secara regular. 


\section{TINJAUAN PUSTAKA}

\section{Biaya Operasional Kapal}

Biaya Operasi Kapal merupakan sejumlah biaya yang dikeluarkan dan diperhitungkan dalam menghasilkan jasa angkutan, meliputi biaya modal untuk kapal, biaya operasional untuk bahan bakar.

Perhitungan biaya operasional kapal menggunakan perhitungan yang sesuai pada KM 73 Tahun 2004, dimana dasar perhitungan adalah sebagai berikut :

a. Produktifitas kapal dalam satu tahun :

Trip per Tahun

$$
=\text { jarak berlayar per trip } \mathrm{x} \text { hari operasi per }
$$

Masa Penyusutan Ekonomis per tahun

Penyusutan Mesin (km)

$$
\begin{aligned}
& =\text { Trip per tahun }(\mathrm{km}) \times \text { umur } \\
& \text { Penyusutan Body Kapal }(\mathrm{km}) \\
& =\text { trip per tahun }(\mathrm{km}) \times \text { umur }
\end{aligned}
$$

b. Biaya Tetap (Fixed Cost)

1) Biaya Penyusutan kapal per Kilometer

a) Mesin kapal

$$
=\frac{\text { Harga Mesin Kapal-(Nilai Residu X Harga Mesin) }}{\text { Penyusutan Mesin per }}
$$
Penyusutan Mesin per km per Tahun

b) Body kapal

$=\frac{\text { Harga Body Kapal-(Nilal Resldu X Harga Body) }}{\text { Penyusutan Body per } \mathrm{km} \text { per Tahun }}$

Total dari jumlah biaya penyusutan kapal adalah

$$
=\text { penyusutan mesin } / \mathrm{km}+\text { penyusutan body } / \mathrm{km}
$$

2) Biaya kepegawaian per Kilometer

3)

a) Gaji Awak kapal

b)

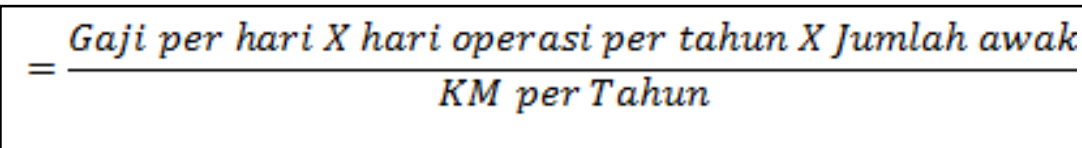

$=\frac{\text { Jumlah awak kapal } X \text { wang makan per hari } X \text { hari operasi }}{}$

KM per Tahun 
4) Biaya kelengkapan Surat kapal

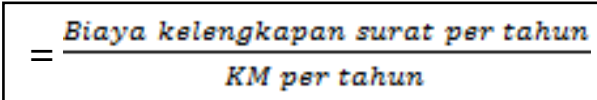

Total biaya kepegawaian per km adalah

= Gaji Awak + Uang makan awak + Biaya kelengkapan surat kapal

Biaya Tidak Tetap (Variable Cost)

5) Biaya bahan bakar

a) Biaya bensin

$=\frac{\text { Pemakaian } B B M / \text { trip } X \text { jumlah } \text { trip/tahun } X \text { harga } B B M / \text { liter }}{\text { trip }}$

b) Biaya oli mesin

= oli mesin per bulan $\times$ harga oli mesin $\times 12$ bulan

$=\frac{\text { pemakaian oli per bulan } X 12 \text { bulan } X \text { harga oli per liter }}{K M \text { per tahun }}$

Total pemakaian bahan bakar per $\mathrm{km}$ :

= Biaya bensin per KM + Biaya Oli mesin per KM

6) Biaya perawatan kapal per $\mathrm{km}$

Tabel II.1

Jenis Perawatan Sesuai dengan Jenis Kapal

\begin{tabular}{|c|l|l|}
\hline No. & JenisPerawatan & $\begin{array}{l}\text { Speed Boat / } \\
\text { Klotok }\end{array}$ \\
\hline 1 & Service Kecil & tiap $10.000 \mathrm{~km}$ \\
2 & Service Besar & tiap $25.000 \mathrm{~km}$ \\
3 & General Over Houll & tiap $60.000 \mathrm{~km}$ \\
\hline No. & JenisPerawatan & Bis Air $\&$ Truk Air \\
\hline 1 & Service Kecil & tiap $15.000 \mathrm{~km}$ \\
2 & Service Besar & tiap $30.000 \mathrm{~km}$ \\
3 & General Over Houll & tiap $75.000 \mathrm{~km}$ \\
\hline
\end{tabular}

Sumber:Lampiran VI KM 73 tahun 2004

7)

$$
\begin{aligned}
& =\frac{\text { Biaya Perawatan per tahun }}{k m \text { Operasi per Tahun }} \\
& \frac{\text { Biaya Clearence } X \text { Trip per tahun }}{\text { km Operasi per Tahun }}
\end{aligned}
$$


Total Biaya Tetap (Total Fixed Cost)

= penyusutan per $\mathrm{km}+$ biaya surat kapal + biaya

Total Biaya Tidak Tetap (Total Variable Cost)

= Biaya BBM + biaya perawatan + biaya clearence

Total BOK $($ Total Cost $=$ TC $)$

= Total biaya tetap + total biaya tidak tetap

III.1.1 Analisa Kondisi yang Ada

Tarif sewa kapal yang ada di dalam kota Palembang dalam hal ini pada lintasan Dermaga BKB - Pulau Kemaro yang berlaku adalah tarif berdasarkan kesepakatan antara operator kapal dengan pengguna jasa atau penumpang. Oleh karena itu, perlu adanya penetapan tarif sewa taksi air yang jelas agar pengguna jasa dan operator taksi air tidak ada yang dirugikan. Untuk menghitung tarif yang ideal maka digunakan Keputusan Menteri NO.73 Tahun 2004 tentang penyelenggaraan Angkutan Sungai Danau dengan menggunakan formulasi perhitungan tarif pada lampiran IV. Dengan demikian maka tarif sewa taksi air dalam kota Palembang dapat diketahui dan akhirya dapat diterapkan di semua UPT dalam kota Palembang.

III.1.2 Analisa Biaya Operasional Kapal

Hasil wawancara yang dilakukan surveyor, dalam 1 tahun kapal yang ada tidak selalu beroperasi, dikarenakan libur hari-hari besar, dan hal lainnya yang menyebabkan kapal tidak beroperasi selama 10 hari untuk Ketek dan 5 hari untuk Speedboat.

1) Biaya Tetap (fixed cost)

a. Biaya penyusutan kapal / tahun

i. Mesin kapal 
Tabel III.5

Biaya Penyusutan Mesin Kapal

\begin{tabular}{|c|c|}
\hline \multicolumn{2}{|c|}{ Mesin Kapal } \\
\hline \multicolumn{2}{|c|}{ (Harga mesin kapal rata - rata - (Nilai Residu X Harga Mesin Rata - rata) } \\
\cline { 2 - 2 } Penyusutan Mesin per KM \\
\hline Rp. 4.210.000 $-(10 \% X$ & Speedboat \\
Rp4.210.000) & Rp. 38.300.000- $(10 \%$ X \\
\cline { 2 - 2 } 22470 KM & Rp.38.300.00) \\
\hline Rp. 169,- per KM & R4940 KM \\
\hline
\end{tabular}

Sumber : Hasil analisa penulis, 2016

ii. Bodi Kapal

Tabel III.6

Biaya Penyusutan Bodi Kapal

\begin{tabular}{|c|c|}
\hline \multicolumn{2}{|c|}{ Bodi Kapal } \\
\hline \multicolumn{2}{|c|}{ Penyusutan bodi kapal rata - rata $-($ nilai residu $\mathbf{x}$ harga bodi rata - rata $)$} \\
\hline KETEK & SPEEDBOAT \\
\hline Rp. $9.450 .000-(10 \% \times 9.450 .000)$ & $\frac{\text { Rp. } 7.150 .000-(10 \% \times 7.150 .000)}{44940 \text { KM }}$ \\
\hline 22470 KM & Rp. 144,- Per KM \\
\hline Rp. 379,- per KM &
\end{tabular}

Sumber : Hasil analisa penulis, 2016

Tabel III.7

Total Biaya Penyusutan Kapal

Total biaya penyusutan kapal

(biaya penyusutan bodi + biaya penyusutan mesin)

\begin{tabular}{ll|l} 
Jenis kapal & Ketek & Speedboat
\end{tabular}

\begin{tabular}{|l|r|r|}
\hline Mesin & Rp. 169,- & Rp. 768,- \\
\hline Bodi & Rp. 379,- & Rp. 144,- \\
\hline Total & Rp. 548,- per KM & Rp. 912,- Per KM \\
\hline
\end{tabular}

Sumber : Hasil analisa penulis, 2016 
b. Biaya Kelengkapan Surat Kapal

Tabel III.11

Biaya Kelengkapan Surat

\begin{tabular}{|c|c|}
\hline \multicolumn{2}{|c|}{$\begin{array}{c}\text { Biaya Kelengkapan Surat Kapal Per Tahun } \\
\text { Biaya kelengkapan surat kapal per tahun }\end{array}$} \\
\hline \multicolumn{2}{|c|}{ km per tahun } \\
\hline Ketek & Speedboat \\
\hline$\frac{\text { Rp. } 100.000}{4494}$ & $\frac{\text { Rp. } 100.000}{8988}$ \\
\hline Rp.23,- per KM per Tahun & Rp. 12,- per KM per Tahun \\
\hline
\end{tabular}

Sumber : Hasil analisa penulis, 2016

Tabel III.12

Biaya Tetap per KM

\begin{tabular}{|r|l|r|r|}
\hline \multirow{2}{*}{ No } & \multicolumn{3}{|c|}{ Total Biaya Tetap Per Km } \\
\cline { 3 - 4 } & \multirow{2}{*}{ Komponen } & \multicolumn{2}{c|}{ Nominal } \\
\cline { 3 - 4 } 1 & BIAYA PENYUSUTAN KAPAL & Rp. $548,-$ & \multicolumn{1}{|c|}{ Speedboat } \\
\hline 2 & BIAYA KEPEGAWAIAN & Rp. 8.761,- & Rp. 4.380,- \\
\hline 3 & BIAYA KELENGKAPAN SURAT KAPAL & Rp 23,- & Rp 12,- \\
\hline \multicolumn{2}{|c|}{ TOTAL } & Rp. 9.332,- & Rp. 5.304,- \\
\hline
\end{tabular}

Sumber : Hasil analisa penulis, 2016

Biaya Tidak Tetap

a.Biaya Bahan Bakar

i. Biaya BBM

Tabel III.13

Biaya Pemakaian Bahan Bakar

Biaya Bahan Bakar Per Km

\begin{tabular}{|c|c|c|cc|c|}
\hline \multicolumn{7}{|c|}{ Biaya Bahan Bakar Per Km } \\
\cline { 2 - 6 } Pemakaian BBM/ trip X jumlah trip / tahun X Harga BBM /liter \\
\hline Jenis kapal & $\begin{array}{c}\text { Jenis } \\
\text { bahan } \\
\text { bakar }\end{array}$ & $\begin{array}{c}\text { pemakaian } \\
\text { per trip }\end{array}$ & $\begin{array}{c}\text { Trip per } \\
\text { tahun }\end{array}$ & $\begin{array}{c}\text { KM per } \\
\text { tahun }\end{array}$ & Biaya bahan bakar \\
\hline Ketek & Solar & 5 liter & 350 & 4494 & Rp 2.337,- per KM \\
\hline Speedboat & Bensin & 10 liter & 700 & 8988 & Rp 6.231,- per KM \\
\hline \multicolumn{3}{|c|}{ Sumber : Hasil analisa penulis, 2016 }
\end{tabular}


Tabel III.14

Biaya Penggunaan Oli

\begin{tabular}{|c|c|c|c|}
\hline \multicolumn{4}{|c|}{$\begin{array}{c}\text { Biaya Oli Per Km } \\
\text { Pemakaian Oli / Bulan X } 12 \text { Bulan X H }\end{array}$} \\
\hline \multicolumn{4}{|c|}{ Km Per Tahun } \\
\hline Jenis kapal & $\begin{array}{c}\text { Pemakaian oli per } \\
\text { bulan }\end{array}$ & $\begin{array}{l}\text { KM per } \\
\text { Tahun }\end{array}$ & Biaya Oli per kM \\
\hline Ketek & 1 liter & 4494 & Rp 54,- per KM \\
\hline Speedboat & 2 liter & 8988 & Rp 54,- per KM \\
\hline
\end{tabular}

Sumber : Hasil analisa penulis, 2016

Harga Oli adalah RP. 20.000,- per liter

Tabel III.15

Total Biaya Bahan Bakar

\begin{tabular}{|c|c|c|}
\hline $\begin{array}{c}\text { Jenis } \\
\text { kapal }\end{array}$ & $\begin{array}{c}\text { biaya bahan bakar per km } \\
\text { (biaya bahan bakar + } \\
\text { biaya oli) }\end{array}$ & $\begin{array}{c}\text { Total Biaya } \\
\text { Bahan Bakar } \\
\text { dan Oli }\end{array}$ \\
\hline Ketek & Rp. 2.337,- + Rp. 54,- & Rp. 2.391,- \\
\hline Speedboat & Rp 6.231,- + Rp. 54,- & Rp. 6.285,- \\
\hline
\end{tabular}

Sumber : Hasil analisa penulis, 2016

b. Biaya Perawatan kapal

Tabel III.16

Biaya Perawatan Kapal

\begin{tabular}{|c|c|c|}
\hline \multirow{2}{*}{$\begin{array}{l}\text { Jenis } \\
\text { Kapal }\end{array}$} & \multicolumn{2}{|c|}{ Biaya perwatan per KM per tahun } \\
\cline { 2 - 3 } & $\frac{\text { Biaya perawatan per bulan X 12 Bulan }}{\text { KM per tahun }}$ & Total biaya \\
\hline Ketek & Rp. $100.000,-$ X 12 Bulan & Rp. 268,- \\
\hline Speedboat & Rp. $100.000 \times 12$ Bulan & Rp. 134,- \\
\hline
\end{tabular}

Sumber : Hasil analisa penulis, 2016

Biaya Clearence (Sandar)/Tahun/Kilometer

Tabel III.17

Biaya Sandar Kapal

\begin{tabular}{|c|c|c|}
\hline \multirow{3}{*}{$\begin{array}{l}\text { Jenis } \\
\text { Kapal }\end{array}$} & \multicolumn{2}{|l|}{ Biaya sandar per trip } \\
\hline & Biaya sandar per trip $X$ Trip per Tahun & Total \\
\hline & KM per tahun & Biaya \\
\hline Ketek & $\begin{array}{c}\text { Rp. } 10.000,- \text { X } 350 \\
4494\end{array}$ & Rp. 779,- \\
\hline Speedboat & $\begin{array}{c}\text { Rp. 10.000,- X } 350 \\
8988\end{array}$ & Rp. 390,- \\
\hline
\end{tabular}

Sumber : Hasil analisa penulis, 2016 
Tabel III.18

Biaya Tidak Tetap per KM

\begin{tabular}{r|r|r|r|}
\multirow{2}{*}{ No } & \multicolumn{3}{|c|}{ Total Biaya Tidak Tetap Per Km } \\
\cline { 2 - 4 } & \multirow{3}{*}{ Komponen } & Ketek & \multicolumn{1}{c|}{ Nominal } \\
\cline { 3 - 4 } & Biaya Bahan Bakar & Rp. 2.391,- & Rp. 6.285,- \\
\hline 1 & Biaya Perawatan & Rp. 268,- & Rp. 164,- \\
\hline 3 & Biaya Sandar & Rp. 779,- & Rp. 390,- \\
\hline \multicolumn{2}{|c|}{ TOTAL } & Rp. 3.438,- & Rp. 6.839,- \\
\hline
\end{tabular}

Sumber : Hasil analisa penulis, 2016

Total Biaya Operasional Kapal per KM per Tahun adalah :

Tabel III.19

Biaya Operasional Kapal per KM

\begin{tabular}{|r|l|r|r|}
\hline \multicolumn{3}{|c|}{ Biaya Operasional Kapal per KM } \\
\hline \multirow{2}{*}{ No } & \multicolumn{1}{|c|}{ Komponen } & \multicolumn{2}{c|}{ Nominal } \\
\cline { 3 - 4 } & ketek & \multicolumn{1}{c|}{ Speedboat } \\
\hline 1 & Total biaya tetap & Rp. 9.332,- & Rp. 5.304,- \\
\hline \multirow{2}{*}{2} & $\begin{array}{l}\text { Total Biaya tidak } \\
\text { tetap }\end{array}$ & Rp. 3.438,- & Rp. 6.839,- \\
\hline \multicolumn{2}{|c|}{ Jumlah } & Rp. 12.770,- & Rp. 12.143,- \\
\hline
\end{tabular}

Sumber : Hasil analisa penulis, 2016

III.1.3 Analisa Tarif Dasar per KM

a.) Tarif Dasar Penumpang per KM

Dari hasil analisa yang didapta mealui metode perhitungan Biaya Operasional Kapal didapati bahwa

1. Tarif dasar Ketek adalah sebesar Rp. 12.770,- per KM

2. Tarif dasar Speedboat adalah sebesar Rp 12.143,-- per KM.

Maka tarif yang diterapkan adalah sebesar :

Tabel III.20

Biaya Operasional Kapal

\begin{tabular}{|c|c|c|c|c|}
\hline No & Jenis Kapal & $\begin{array}{c}\text { Tarif Bok Per } \\
\text { Km }\end{array}$ & $\begin{array}{c}\text { Keuntungan } \\
10 \%\end{array}$ & Total Tarif \\
\hline 1 & Ketek & RP. 12.770,- & Rp. 1.277,- & $\begin{array}{c}\text { Rp. 14.047,-/KM } \\
\text { Atau } \\
\text { pembulatan } \\
\text { Rp. 15.000,-/KM }\end{array}$ \\
\hline 2 & Speedboat & Rp. 12.143,- & Rp. 1.214,- & $\begin{array}{c}\text { Rp. 13.357,-/KM } \\
\text { Atau } \\
\text { Pembulatan } \\
\text { RP. 14.000,-/KM }\end{array}$ \\
\hline
\end{tabular}

Sumber : Hasil analisa penulis, 2016 


\section{III.1.4 Analisa Wilingnes To Pay}

b.) Tarif atas dasar Penumpang dan konsumen(WTP dan ATP)

Dari hasil survai yang didapatkan atas dasar keinginan membayar dari kunsumen atau pelanggan bahwa ternyata kemampuan dan keinginan konsumen lebih mahal dari perhitungan tariff yang didapatkan dari hasil survai secara lebih lengkap dapat dilihat pada tabel berikut ini.

Tabel Willingness to Pay Consument

\begin{tabular}{|c|c|c|c|}
\hline No. & Jenis Kapal & Lama Pemakaian & $\begin{array}{c}\text { Keinginan } \\
\text { Biaya }\end{array}$ \\
\hline \multirow{3}{*}{1} & \multirow{3}{*}{ Getek } & $1 \mathrm{Jam}$ & Rp. 150.000 \\
\hline & & 2 Jam & Rp. 200.000 \\
\hline & & $3 \mathrm{Jam}$ & Rp. 350.000 \\
\hline \multirow{4}{*}{2} & \multirow{4}{*}{ Speed Boat } & 30 Menit & Rp. 150.000 \\
\hline & & $1 \mathrm{Jam}$ & Rp. 200.000 \\
\hline & & $2 \mathrm{Jam}$ & Rp. 350.000 \\
\hline & & $3 \mathrm{Jam}$ & Rp. 400.000 \\
\hline \multirow{4}{*}{3} & \multirow{4}{*}{ Kapal Wisata } & $1 \mathrm{Jam}$ & Rp. 200.000 \\
\hline & & $2 \mathrm{Jam}$ & Rp. 300.000 \\
\hline & & $3 \mathrm{Jam}$ & Rp. 400.000 \\
\hline & & 4 Jam & Rp. 600.000 \\
\hline
\end{tabular}

Hasil Analisis Survei 2017.

III.1.5 Perbandingan Harga.

Harga Rp/Km \& WTP dengan Pengelola:

\begin{tabular}{|c|c|c|c|}
\hline \multirow{2}{*}{ No } & \multirow{2}{*}{ Perbandingan } & \multicolumn{2}{|c|}{ Rp/Km } \\
\cline { 3 - 4 } & & Getek (Rp) & $\begin{array}{c}\text { Speed Boat } \\
(\mathbf{R p})\end{array}$ \\
\hline \multirow{2}{*}{1} & \multirow{2}{*}{ Perhitungan Tarif/ Km 73/2004 } & 12.770 & 12.143 \\
\cline { 3 - 4 } 2 & WTP & 15.000 & 18.000 \\
\cline { 3 - 4 } & & & 19.859 \\
\hline
\end{tabular}

Dan ternyata antara harga yang diinginkan pengelola angkutan dengan konsumen hamper mempunyai nilai yang harga tidak banyak berbeda atau tidak lebih dari 5 persen dan bila dibandingkan dengan hasil perhitungan berdasarkan jarak perkilometer $(\mathrm{rp} / \mathrm{km})$ yang mempunyai deviasi lebih besar dari 45 persen.

\section{III.2 Pemecahan Masalah}

Berdasarkan Hasil analisa yang telah dilakukan, maka didapatkan besarnya Biaya Operasional Kapal per Kilometer pada lintasan dermaga BKB - Pulau Kemaro untuk masing masing kapal adalah : 
Tabel III.21

Perbandingan analisa tarif sekarang dan seharusnya

\begin{tabular}{|c|c|c|}
\hline Jenis kapal & $\begin{array}{c}\text { Analisas kondisi } \\
\text { sekarang }\end{array}$ & $\begin{array}{c}\text { Analisa kondisi } \\
\text { seharusnya }\end{array}$ \\
\hline Ketek & $\begin{array}{c}\text { Rp. 207.500,- } \\
\text { /kapal/trip }\end{array}$ & $\begin{array}{c}\text { Rp. 192.600,- } \\
\text { /kapal/trip }\end{array}$ \\
\hline Speedboat & $\begin{array}{c}\text { Rp. 255.000,- } \\
\text { /kapal/trip }\end{array}$ & $\begin{array}{c}\text { Rp. 179.760,- } \\
\text { /kapal/trip }\end{array}$ \\
\hline
\end{tabular}

Sumber : Hasil analisa penulis, 2016

Berdasarkan Studi kasus yang dilakukan untuk mencari tarif taksi air per kilometer berdasarkan Biaya Operasional Kapal per Kilometer dalam kota Palembang dan maka diperoleh hasil sebagai berikut :

Tabel III.22

Kesesuaian Tarif

\begin{tabular}{|c|c|c|}
\hline Jenis kapal & Tarif yang Berlaku & Tarif Rencana \\
\hline Ketek & Rp.16.160,-/Km & Rp. 15.000,-/Km \\
\hline Speedboat & Rp.19.859,-/Km & Rp. $14.000,-/ \mathrm{Km}$ \\
\hline
\end{tabular}

Sumber : Hasil analisa penulis, 2016

Bila hasil perhitungan tariff hasil survai kita kaji lebih jauh ternyata ada kesenjangan yang sangat mencolok dari hasil perhitungan tersebut nilai yang dininginkan konsumen dan operator cukup tinggi bedanya dengan tariff rupiah perkilometer dan hasilnya dapat dilihat pada tabel berikut :

Tabel III 2.3

Perbandingan Harga Rp/Km \& WTP dengan Pengelola:

\begin{tabular}{|c|c|c|c|}
\hline \multirow[b]{2}{*}{ No } & \multirow[b]{2}{*}{ Perbandingan } & \multicolumn{2}{|c|}{$\mathbf{R p} / \mathbf{K m}$} \\
\hline & & Getek (Rp) & $\begin{array}{c}\text { Speed Boat } \\
\text { (Rp) }\end{array}$ \\
\hline 1 & $\begin{array}{l}\text { Perhitungan Tarif/ Km } \\
73 / 2004\end{array}$ & 12.770 & 12.143 \\
\hline & Kesenjangan & & $48 \%$ \\
\hline 2 & WTP & 15.000 & 18.000 \\
\hline & kesenjangan & & $56 \%$ \\
\hline 3 & Pengelola Angkutan & 16.160 & 19.859 \\
\hline
\end{tabular}

Dengan kesenjangan nilai harga yang cukup signifikan yaitu 48 persen antara tarip $\mathrm{rp} / \mathrm{km}$ dengan keinginan membayar pengguna jasa (konsumen) serta tariff yang digunakan oleh operator hingga mencapai kesenjangan 56 persen, ini menunjukkan bahwa perhitungan tariff yang digunakan dalam KM 73 tahun 2008 yang digunakan sekarang tidak meng akomodir kemampuan bayar para pengguna jasa angkutan serta keinginan dari penyedia jasa angkutan sungai untuk 
pariwisata sungai musi baik itu untuk angkutan getek,maupun speedboat seerta bus air yang kini sedang operasi melayani angkutan dalam wilayah perkotaan sungai musi.

Untuk pemecahan masalah yang terjadi saat ini ada beberapa upaya yang perlu dilakukan pemerintah kota Palembang maupun Kementrian perhubungan sebagai Pembina teknis atau penyusun peraturan Mentri tentang tariff secara Nasional. Yaitu :

1. Melakukan penyyusunan Peraturan Mentri Perhubungan Khusus untuk angkutan wisata.

2. Merevisi KM 73 tahun 2008 tentang tariff angkutan sungai agar dapat berlaku secara universal.

3. Memberikan subsidi bagi pengusaha angkutan wisata angkutan sungai agar pendapatan para operator lebih memberikan keuntungan bagi mereka.

\section{IV.Kesimpulan}

Berdasarkan Analisa yang dilakukan Penulis, dapat disimpulkan:

1. Tarif taksi air yang diperoleh berdasarkan perhitungan Biaya Operasional Kapal yang terdapat pada Lampiran VI KM Nomor 73 Tahun 2004 Tentang Penyelenggaraan Angkutan Sungai dan Danau adalah sebesar Rp. 15.000,- per KM untuk kapal jenis ketek dan Rp. 14.000,- per KM untuk jenis 1 speedboat

2. Tarif berdasarkan perhitungan BOK pada 2 jenis taksi air lebih rendah Rp.1.160,- per KM untuk kapal ketek dan Rp. 5.859,- per KM speedboat.

3. Ada kesenjangan yang cukup tinggi antara perhitungan tariff yang berdasarkan Keputusan menteri perhubungan No 73 Tahun 2004, bila dibandingkan dengan Kemampuan bayar penumpang hingga 48,6 persen dan bila dibandingkan tariff $\mathrm{rp} / \mathrm{km}$ ( KM 73 Tahun 2004) dengan tariff yang diberlakukan oleh operator atau pengusaha angkutan wisata sungai kesenjangannya bisa mencapai 56 persen.

\section{Saran}

Berdasarkan analisa yg dilakukan penulis, dapat diberikan saran-saran sebagai berikut:

1. Perlu adanya penetapan dari Pemerintah untuk tarif sewa taksi air di dalam kota Palembang agar tidak ada pihak yang merasa dirugikan baik itu Pengguna jasa maupun pihak penyedia jasa.

2. Perlu adanya pengawasan dari Pemerintah terhadap tarif yang berlaku sesuai KM 73 Tahun 2004 tentang Penyelenggaraan angkutan Sunngai Danau

3. Melakukan penyyusunan Peraturan Mentri Perhubungan Khusus untuk angkutan wisata.

4. Merevisi KM 73 tahun 2004 tentang tariff angkutan sungai agar dapat berlaku secara univers 


\section{DAFTAR PUSTAKA}

,2015, Palembang dalamAngka, Badan Pusat Statistik, Kota Palembanga.

,1987, Himpunan Istilah Perhubungan, Badan Penelitian dan Pengembangan Perhubungan, Jakarta.

.2004. Keputusan Mentri Perhubungan NO 73 Tahun 2004, Jakarta.

AS, Chaidirrozi, 2002, Operasional Pelabuhan ASDP, Balai Pendidikan dan

Pelatihan Perhubungan Lalu Lintas Angkutan Sungai, Danau dan Penyeberangan, Palembang.

Salim, Abbas, 1992, Manajemen Transportasi, Ghalia Indonesia, Jakarta.

Supranto, Johannes, 1990, Statistik Teori dan Aplikasi, Erlangga, Jakarta. 